\title{
PENERAPAN ASSERTIVE BEHAVIOR THERAPY UNTUK MENURUNKAN PERILAKU AGRESI VERBAL PADA ANAK DI LEMBAGA X
}

\author{
Stevani $^{1}$, Debora Basaria ${ }^{2}$ dan Florencia Irena ${ }^{3}$ \\ ${ }^{1}$ Fakultas Psikologi, Universitas Tarumanagara Jakarta \\ Email: stevs.vani@gmail.com \\ ${ }^{2}$ Fakultas Psikologi, Universitas Tarumanagara Jakarta \\ Email: deborab@fpsi.untar.ac.id \\ ${ }^{3}$ Fakultas Psikologi, Universitas Tarumanagara Jakarta \\ Email: florenciairena@ymail.com
}

\begin{abstract}
ABSTRAK
Pada masa anak usia sekolah dasar, mereka sering melakukan perilaku agresi secara verbal kepada teman maupun orangtua. Perilaku agresi secara verbal dapat diintervensi dengan assertive behavior therapy (ABT). ABT mengajarkan anak untuk berperilaku dengan menyertakan beberapa faktor dalam meningkatkan kompetensi sosial yaitu dari faktor kognitif, emosi, dan perilaku. Anak akan diberikan beberapa cerita mengenai kehidupan sehari-hari dan anak akan diajak untuk berpartisipan dalam cerita tersebut. ABT yang diterapkan pada penelitian ini merupakan upaya untuk menurunkan perilaku agresi verbal dari 5 anak putra di lembaga X. Kelima anak ini berasal dari keluarga dengan kondisi ekonomi rendah dan mendapatkan dukungan yang terbatas dari keluarga. Mereka seringkali menampilkan perilaku negatif, yaitu melakukan perilaku agresi secara verbal kepada teman-temannya. Kelima anak ini juga sering menganggu pembelajaran di dalam kelas dan membuat kelas menjadi ribut. Penelitian ini menggunakan quantitative one group pre-test post-test design dimana alat ukur skala Aggression Medinus \& Johnson. Alat ukur ini digunakan untuk mengetahui perbandingan hasil sebelum dan sesudah pemberian intervensi. ABT yang akan dijalankan berjumlah 6 sesi, di mana masing-masing sesi berlangsung selama -/+ 45 menit. Total skor dari lima partisipan mengalami penurunan agresi secara verbal. Hasil penelitian menunjukkan bahwa Assertive Behavior Therapy dapat menurunkan perilaku agresi verbal dari lima putra di lembaga ' $X$ '.
\end{abstract}

Kata kunci: assertive behavior therapy, agresi, agresi verbal.

\section{PENDAHULUAN}

\section{Latar Belakang}

Anak-anak usia sekolah dasar atau periode middle childhood, umumnya berada dalam proses perkembangan yang berlangsung dengan cepat dalam aspek fisik, emosional, intelektual dan sosial. Dalam tahap perkembangan tersebut, tak jarang anak mengalami hambatan atau bahkan melakukan perilaku yang keliru yang dapat merugikan mereka, baik untuk dirinya sendiri maupun orang lain. Perilaku yang dicerminkan dapat berupa perilaku yang positif dan perilaku yang negatif, salah satunya yaitu berupa perilaku kenakalan. Kenakalan pada anak dimaknai sebagai suatu bentuk perilaku yang tidak sesuai dengan norma-norma yang hidup di tengah masyarakat. Pada umumnya, kenakalan merupakan produk konstitusi defektif dari mental dan emosi, yaitu mental dan emosi anak yang belum matang (labil) dan rusak (defektif) sebagai akibat proses pengkondisian oleh lingkungan yang buruk (Kartono, 2007).

Siswa di Sekolah Dasar (SD) akan mengalami masalah-masalah yang berkenaan dengan perkembangan individu, dan perbedaan individu dalam hal kecerdasan, kecakapan, hasil belajar, bakat, sikap, kebiasaan, pengetahuan, kepribadian, cita-cita, kebutuhan, minat, pola-pola, dan tempo perkembangan, ciri-ciri jasmaniah dan latar belakang lingkungan. Terdapat juga perbedaan kebutuhan individu dalam hal memperoleh kasih sayang, memperoleh harga diri, memperoleh penghargaan yang sama, ingin dikenal, memperoleh prestasi dan posisi, untuk dibutuhkan orang lain, merasa bagian dari kelompok, rasa aman dan perlindungan diri, dan untuk memperoleh kemerdekaan diri. Adanya perbedaan penyesuaian diri, yang salah satunya juga mempengaruhi 
perbedaan tingkah laku. Muncul juga masalah belajar dalam diri anak.

Perilaku yang sering terjadi pada anak adalah perilaku agresi. Perilaku agresi secara psikologis cenderung menyerang sesuatu yang dipandang sebagai hal yang mengecewakan, menghalangi atau menghambat. Perilaku ini terjadi pada masa perkembangan, karena pada masa inilah seorang anak sudah mulai merasa ingin mengetahui dan ingin melakukan sesuatu yang dia inginkan walaupun tanpa dia sadari sesuatu yang dia lakukan itu dapat berdampak negatif pada dirinya sendiri ataupun pada orang lain. Seorang anak dapat berperilaku agresi sebagai respons untuk melindungi diri terhadap suatu provokasi atau kesulitan tertentu yang disertai dengan perasaan marah atau melakukannya karena bertujuan untuk sengaja menyakiti orang lain untuk mendapatkan suatu objek, mengintimidasi, atau mendominasi orang lain (Crick \& Dodge dalam Camodeca, Goossens, Terwogt, \& Schuengel, 2002).

Perilaku agresi anak muncul manakala anak merasakan adanya ancaman, marah, gusar, atau frustrasi. Perilaku agresi sesungguhnya merupakan reaksi normal pada anak-anak yang masih kecil. Anak-anak secara naluriah akan memunculkan perilaku ini ketika mereka merasa tidak nyaman, ketika mereka ingin melindungi diri mereka, atau ketika mereka ingin mencapai suatu tujuan tertentu namun tidak mengetahui bagaimana cara yang lebih baik untuk meraihnya. Selain itu, perilaku agresi juga merupakan cara khas anak kecil untuk menunjukkan kepada orang lain bahwa mereka tidak suka pada apa yang dilakukan orang lain terhadap mereka. Akan tetapi, seiring dengan bertambahnya usia mereka, anak-anak seharusnya menjadi semakin mampu menggunakan cara-cara yang lebih tepat untuk meraih tujuannya, sehingga tidak perlu bertindak dengan cara yang agresi. Perilaku agresi menjadi bagian dari tahapan perkembangan mereka dan sering kali menimbulkan masalah, baik itu di rumah, sekolah ataupun dalam suatu kelembagaan yang mana disuatu tempat tersebut dia dapat berinteraksi terutama dengan orang lain. Diharapkan setelah melewati usia 7 tahun, anak sudah lebih dapat mengendalikan dirinya untuk tidak menyelesaikan masalah dengan perilaku agresi.

Perilaku agresi yang menyebabkan sakit fisik (nonverbal) antara lain memukul, menggigit, mencubit, menendang, menginjak, melempari orang dengan benda, dan sebagainya. Sedangkan secara psikis (verbal), diantaranya mengucapkan kata-kata hinaan atau mengejek, memaki dengan kata-kata kotor, melecehkan, mengancam, membentak orang yang lebih tua, atau bahkan memerintah orang lain seenaknya. Dengan adanya perubahan baik dari sisi seksual, psikologis maupun sosial membuat masa anak- anak seringkali menjadi masa-masa rawan terjadinya adanya perilaku agresi yang diakibatkan kurangnya bimbingan orang tua, kurangnya perhatian guru, pengaruh lingkungan, pergaulan yang tidak baik atau kurangnya perhatian dari orang tua adanya pola asuh anak yang dapat mempengaruhi semua ini (Pohan, 1986).

Perilaku agresi secara verbal salah satunya dapat diintervensi dengan assertive behavior therapy (ABT). Dalam hal ini, assertive behavior therapy, yang biasa dikenal juga dengan assetiveness training, assertion training, atau social skills training, merupakan prosedur melatih seseorang dalam hal berperilaku sosial yang tepat untuk mengekspresikan perasaan, tindakan, opini, dan haknya, yang berakar pada terapi perilaku. ABT mengajarkan anak untuk berperilaku dengan menyertakan beberapa faktor dalam meningkatkan kompetensi sosial yaitu dari faktor kognitif, emosi, dan perilaku. Anak akan diberikan beberapa cerita mengenai kehidupan sehari-hari dan anak akan diajak untuk berpartisipan dalam cerita tersebut.

Penelitian dari Zare dan Faharani (2018) mengenai ABT yang dilakukan dengan metode training dapat membantu para suster dalam mengatur kemarahan mereka saat mereka sedang bekerja di 
rumah sakit. Selain itu, juga ada penelitian di Indonesia yang dilakukan oleh Keliat (2015) mengenai ABT yang dapat membantu mengurangi terjadinya bullying pada sesama rekan kerja yang berada di Jawa Barat. Dalam penelitian ini ditemukan bahwa ABT juga dapat diberikan untuk menurunkan perilaku agresi untuk pekerja di perusahaan yang sering kesulitan dalam mengontrol emosi mereka.

Berdasarkan penelitian sebelumnya menyatakan bahwa ABT dapat mengurangi dan membantu perilaku negatif yang terjadi. Oleh karena itu, anak-anak dengan perilaku agresi secara verbal akan dihadapkan pada berbagai situasi interpersonal yang menantang seperti menuntut orang lain, menolak permintaan orang lain, mengatasi perasaan mereka sendiri dan perasaan orang lain, memberi dan menerima pujian, berteman, mengatasi kritik, dan mengelola stres dengan cara yang tepat dan benar (Rotheram, Bickford, \& Miller, 2001). Perilaku agresi secara verbal yang tinggi adalah perilaku di mana emosi yang dialami anak-anak dalam situasi stres. Anak-anak perlu mengatasi emosi ini untuk mengembangkan kompetensi sosial. Keterampilan ini bersifat internal dan harus dimulai sendiri agar efektif. Anak diajarkan agar dapat mengekspresikan sesuatu dengan bentuk yang lebih benar dan tidak menyakiti orang lain.

Saat ini, lembaga X yang merupakan tempat pembelajaran bagi anak-anak dengan latar belakang sosial ekonomi rendah. Pada tanggal 30 Oktober 2017, salah satu guru dari kelas 3 SD merujuk 5 orang anak yaitu R, A, M, W, dan F untuk mengikuti pemeriksaan psikologis sebagai bentuk evaluasi terhadap perilaku mereka. Kelima anak ini seringkali menampilkan perilaku negatif, yaitu melakukan perilaku agresi secara verbal kepada teman-temannya. Kelima anak ini juga sering menganggu pembelajaran di dalam kelas dan membuat kelas menjadi ribut. Oleh karena itu, peneliti ingin melaksanakan proses terapi dengan pendekatan assertive behavior therapy untuk mengurangi perilaku agresi verbal pada kelima anak. Pelatihan ini bertujuan agar anak dapat berperilaku dengan menyertakan beberapa faktor dalam meningkatkan kompetensi sosial yaitu dari faktor kognitif, emosi, dan perilaku. Maka, tujuan dari penelitian ini adalah menerapkan dan mencari tahu apakah penerapan assertive behavior therapy dapat menurunkan perilaku agresi verbal pada anak di lembaga $X$.

\section{METODE PENELITIAN}

\section{Partisipan}

Penelitian ini melibatkan lima individu yang memiliki karakteristik sebagai berikut: (a) berada dalam tahapan usia middle childhood (8-10 tahun) yang duduk di bangku kelas 3 SD, (b) mengikuti kegiatan di Lembaga X karena kondisi ekonomi keluarga rendah,(c) memperoleh skor IQ dalam rentang rata-rata, (d) melakukan perilaku agresi secara verbal.

\section{Desain penelitian}

Design penelitian yang digunakan adalah quantitative one group pre-test post-test design, yaitu metode kuantitatif dengan menggunakan pre-test dan post-test yang berguna untuk melihat apakah ada penurunan pada agresi verbal sebelum dan sesudah intervensi diberikan.

\section{Setting lokasi}

Penelitian dilakukan di ruang kelas lembaga ' $X$ ' yang memiliki misi membantu anak-anak dari keluarga yang kurang mampu khususnya dalam bidang pendidikan, seperti biaya sekolah, biaya peralatan sekolah, dan penyediaan les bagi anak-anak sekolah di daerah Cilincing. 


\section{Perlengkapan penelitian}

Selama melakukan penelitian, penulis memerlukan lembar biodata, lembar informed consent, buku persoalan CFIT dan lembar jawaban, dan lembar kuesioner skala perilaku agresif dari Medinus dan Johnson (1976), serta alat tulis.

\section{Pengukuran}

Skala perilaku agresi adalah satu instrumen yang dikembangkan oleh Medinus \& Johnson (1976) untuk mengukur tingkat agresi yang kemudian diadaptasi di Indonesia oleh Kristianto (2012). Instrumen ini terdiri dari 42 item pernyataan yang didasari oleh bentuk-bentuk perilaku agresi yaitu fisik dan verbal yang dikembangkan oleh Medinus \& Johnson (1976). 12 dari 42 item pernyataan merupakan reverse scored items ("Saya menghindari perbuatan merusak benda atau barang teman saya jika sedang marah terhadapnya"). Setiap item pertanyaan memiliki tiga pilihan respons yang harus dipilih berdasarkan frekuensi individu melakukan kondisi pada pernyataan, yaitu pilihan bahwa anak sering melakukannya, kadang-kadang melakukannya, atau tidak pernah melakukannya.

Selain itu, juga digunakan Tes grafis dilakukan untuk mengetahui pertumbuhan kepribadian anak dan mengetahui konsep diri yang dimiliki. Selain itu, tes grafis juga digunakan untuk melihat indikasi agresi pada anak. Analisa gambar dilakukan berdasarkan beberapa prinsip interpretasi Ogdon (1974).

\section{HASIL DAN PEMBAHASAN}

\section{Gambaran partisipan}

Secara umum, kelima partisipan ini berusia middle childhood yang duduk di bangku kelas 3 SD dan telah menjadi murid di Lembaga "X" minimal 1 tahun lamanya. Skor IQ yang dibutuhkan adalah berada dalam rentang rata-rata. Dalam tes grafis, anak cenderung menggambar bentukbentuk yang tajam dan tekanan garisnya kuat. Selain itu, anak menunjukkan sikap non asertif saat berada di kelas, yaitu sikap komunikasi aktif yang berupa perilaku agresi verbal, seperti berbicara secara berlebihan, berkata kasar kepada teman, dan sering mengejek teman-teman di kelas.

\section{Pelaksanaan intervensi}

Intervensi dilakukan kepada subyek dengan inisial A, F, M, R, dan W. Dalam intervensi, kelima subyek konsisten untuk hadir dalam sesi-sesi pertemuan. Sebelum melakukan intervensi, penulis melakukan terlebih dahulu melakukan screening berupa autoanamnesa, pemberian kuesioner mengenai agresifitas dan tes grafis (Draw a Man) untuk mengetahui tingkat agresifitas, bentuk agresifitas dan gejala agresifitas yang ditampilkan subyek. Demikian pula setelah intervensi selesai dilakukan diberikan post test untuk kelima subyek kembali dilakukan autoanamnesa, pemberian kuesioner dan tes grafis (DAM) untuk mengevaluasi adanya penurunan agresifitas yang dialami oleh masing-masing subyek. Intervensi yang akan dijalankan berjumlah 6 sesi, di mana masingmasing sesi berlangsung selama -/+ 45 menit. Adapun rincian kegiatan didasarkan pada 4 tahapan yang perlu dilakukan dalam assertive behavior therapy (Rotheram, Bickford, \& Miller, 2001) 
Tabel 1. Prosedur Intervensi

\begin{tabular}{lll}
\hline Tahap & Sesi & Treatment \\
\hline Perkenalan & 1 & Positive \\
dan warm- & & Activity \\
up & &
\end{tabular}

Tujuan Teknik

Mengenal dan
menyebutkan katakata positif untuk diri sendiri

\section{Partisipan}

Paminta untuk menulis dan

menghias kata positif tersebut di atas

kertas berwarna. Partisipan akan menempelkannya dikertas yang terdapat foto dari partisipan dan menaruh kata positif tersebut di bawah foto masingmasing partisipan

\begin{tabular}{|c|c|c|c|}
\hline $\begin{array}{l}\text { Saying good } \\
\text { things about } \\
\text { my self }\end{array}$ & 2 & $\begin{array}{l}\text { Story } \\
\text { Telling }\end{array}$ & $\begin{array}{l}\text { Menimbulkan hal } \\
\text { positif dalam diri }\end{array}$ \\
\hline & & $\begin{array}{l}\text { Activity for } \\
\text { my self }\end{array}$ & $\begin{array}{l}\text { Menghilangkan } \\
\text { hal negatif dalam } \\
\text { diri anak }\end{array}$ \\
\hline $\begin{array}{l}\text { Saying good } \\
\text { things about } \\
\text { other people }\end{array}$ & 3 & Scribble & $\begin{array}{l}\text { Menghilangkan } \\
\text { rasa marah pada } \\
\text { orang lain }\end{array}$ \\
\hline
\end{tabular}

Partisipan mendengar cerita dan memerankan adegan cerita dengan menambahkan pikiran positif yang muncul untuk adegan tersebut.

Partisipan diminta untuk menuliskan kata negatif di kertas dan melipat kertas tersebut serta melepaskan kapal tersebut di sungai sambil berafirmasi.

Group leader akan memberikan setiap partisipan 1 lembar kertas A3 dan 1 set crayon. Group leader akan mengatakan kepada anak saat mereka diejek, dimarahi, dan diperlakukan yang mereka tidak suka. Mereka harus meluapkannya ke dalam kertas tersebut, partisipan diminta untuk mencoret-coret kertas secara berulang-ulang hingga kertas tersebut penuh

Story Menyadari Partisipan mendengar cerita dan diminta

Telling pentingnya suatu untuk memberikan alasan mengapa kita pujian harus memuji orang lain bukan menghina atau menjelekkan orang lain. Partisipan juga diajak untuk memberikan alasan apa dampak dari memberikan hal positif kepada orang lain

Activity for Mengenal dengan Masing-masing partisipan diberikan other memberikan hal kertas sebanyak 6 dan diminta untuk positif bagi orang menuliskan hal positif dalam diri setiap lain anggota. Setelah menuliskan hal postif, kertas tersebut diberikan kepada orang yang bersangkutan dan orang tersebut membaca di dalam hati.

\begin{tabular}{llll}
\hline $\begin{array}{l}\text { What a face } \\
\text { tell me }\end{array}$ & $\begin{array}{l}\text { Story } \\
\text { Telling }\end{array}$ & $\begin{array}{l}\text { Mengetahui } \\
\text { ekspresi dan emosi } \\
\text { secara tepat }\end{array}$ & $\begin{array}{l}\text { Group leader akan memerankan adegan } \\
\text { dengan respon dan emosi yang berbeda } \\
\text { atau tidak tepat. Partisipan diminta } \\
\text { mencari hal yang tidak tepat dari dalam } \\
\text { cerita tersebut }\end{array}$ \\
\hline
\end{tabular}




\begin{tabular}{|c|c|c|c|c|}
\hline & & Drama & 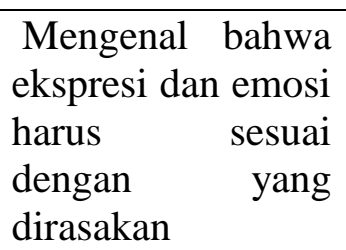 & $\begin{array}{l}\text { Partisipan mengambil secara acak } \\
\text { adegan-adegan yang akan mereka } \\
\text { perankan. Partisipan harus memerankan } \\
\text { peran tersebut dengan ekspresi wajah } \\
\text { yang tampak }\end{array}$ \\
\hline \multirow[t]{2}{*}{$\begin{array}{l}\text { Please } \\
\text { control } \\
\text { anger }\end{array}$} & 5 & $\begin{array}{l}\text { Story } \\
\text { Telling }\end{array}$ & $\begin{array}{l}\text { Mengenal dan } \\
\text { mengetahui } \\
\text { dampak dari emosi } \\
\text { negatif }\end{array}$ & $\begin{array}{l}\text { Partisipan menonton film mengenai anak } \\
\text { yang sedang marah dan dampak bagi } \\
\text { dirinya dan orang lain }\end{array}$ \\
\hline & & Blow & $\begin{array}{l}\text { Mengontrol emosi } \\
\text { negatif dalam diri }\end{array}$ & $\begin{array}{l}\text { Partisipan diminta untuk meniup balon } \\
\text { lem dengan ukuran sedang. Group leader } \\
\text { akan menyebutkan peristiwa yang } \\
\text { membuat anak marah dan anak harus } \\
\text { meniup balon lem tersebut hingga besar. }\end{array}$ \\
\hline \multirow[t]{3}{*}{$\begin{array}{l}\text { Terminatio } \\
n\end{array}$} & 6 & $\begin{array}{l}\text { Evaluasi } \\
\text { tujuan } \\
\text { partisipan }\end{array}$ & $\begin{array}{l}\text { Melihat manfaat } \\
\text { yang diperoleh } \\
\text { partisipan dari sesi } \\
\text { terapi yang telah } \\
\text { dilalui. }\end{array}$ & $\begin{array}{l}\text { Membuat sebuah cerita mengenai } \\
\text { dirinya setelah mengikuti terapi dan } \\
\text { menceritakan mengenai dirinya di depan } \\
\text { teman-teman yang lainnya. }\end{array}$ \\
\hline & & Calm down & $\begin{array}{l}\text { Mengetahui cara } \\
\text { yang tepat untuk } \\
\text { menenangkan diri }\end{array}$ & $\begin{array}{l}\text { Anak diajarkan membuat bola yang } \\
\text { dapat diremas saat sedang marah. Balon } \\
\text { digambar muka senyum dan dimasukkan } \\
\text { tepung di dalam balon dan diberikan air. }\end{array}$ \\
\hline & & Discussion & $\begin{array}{lr}\text { Menyadari } & \text { bahwa } \\
\text { emosi } & \text { negatif } \\
\text { dapat diganti } \\
\text { dengan emosi yang } \\
\text { lebih positif }\end{array}$ & $\begin{array}{l}\text { Anak diajak mencari hal yang dapat } \\
\text { membuat mereka merasa lebih tenang }\end{array}$ \\
\hline
\end{tabular}

\section{Hasil intervensi}

Intervensi kelompok dengan menggunakan pendekatan assertive behavior therapy dapat menurunkan kecenderungan agresi secara verbal pada kelima subyek, tetapi belum menyeluruh. Penurunan kecenderungan agresi dapat terlihat dari hasil tes grafis DAM. Selain itu, dilengkapi juga dari hasil wawancara terhadap subyek setelah dilakukannya intervensi. Kelima subyek menunjukkan penurunan kecenderungan agresi, yaitu dengan digambarkannya leher, tangan, jari, dihilangkannya gambar gigi dan taring, dan dengan ekspresi tersenyum. Selain itu, intervensi kelompok ini juga bermanfaat terhadap relasi antara kelima subyek. Relasi antara kelima subyek mengalami perubahan ke arah yang lebih positif. Menurut Papalia, Olds dan Feldman (2009) menyatakan bahwa hasil dari intervensi kelompok biasanya dikarenakan adanya faktor dari teman sebaya di mana teman sebaya dapat memberikan pengaruh penting, baik positif maupun negatif sehingga satu sama lain dapat mengalami perubahan yang ke arah lebih positif. 
Tabel 3. Hasil Intervensi per sesi

\begin{tabular}{|c|c|}
\hline Sesi & Keterangan \\
\hline Pertama & $\begin{array}{l}\text { Saat sesi pertama berlangsung, semua partisipan masih terlihat sering berperilaku } \\
\text { agresi verbal. Kelima partisipan terlihat sering berbicara berlebihan saat partisipan } \\
\text { lain sedang berbicara. Mereka juga berbicara dengan volume suara yang keras. Saat } \\
\text { ditetapkan peraturan, A dan F terlihat diam dan mengikuti instruksi yang diberikan }\end{array}$ \\
\hline Kedua & $\begin{array}{l}\text { Kelima partisipan masih memiliki penbendaharaan kata positif yang sedikit dan } \\
\text { mereka kesulitan dalam menulis kalimat postif. Mereka lebih tertarik dan } \\
\text { mengerjakannya dengan cepat saat diminta menuliskan kata negatif yang pernah } \\
\text { mereka sebutkan. Mereka juga terlihat sangat antusias saat melepaskan kapal ke } \\
\text { sungai terdekat. }\end{array}$ \\
\hline Ketiga & $\begin{array}{l}\text { Kelima partisipan terlihat menunjukkan perilaku agresi ketika diminta untuk } \\
\text { mencoret-coret menggunakan crayon. Mereka menyoret dengan sangat kuat hingga } \\
\text { semua crayon menjadi patah dan tangan dari masing-masing partisipan terlihat } \\
\text { merah serta mereka kesakitan saat melakukan hal tersebut. F, M, dan W mulai } \\
\text { nyaman di dalam kelompok dan menjawab secara aktif saat diberikan pertanyaan. }\end{array}$ \\
\hline Keempat & $\begin{array}{l}\text { Kelima partisipan dapat memerankan ekspresi dan emosi secara tepat. Bahkan, } \\
\text { mereka dapat membedakan ekspresi dan emosi yang tidak tepat dalam cerita. Kata } \\
\text { positif yang diucapkan oleh } \mathrm{A}, \mathrm{F} \text {, dan } \mathrm{M} \text { mulai bervariasi dan lebih banyak. } \\
\text { Sedangkan } \mathrm{R} \text { dan } \mathrm{W} \text { masih kesulitan dalam menyebutkan kata positif yang diminta } \\
\text { dan masih bersifat monoton. }\end{array}$ \\
\hline Kelima & $\begin{array}{l}\text { A, F, dan } \mathrm{M} \text { dapat secara perlahan-lahan mengeluarkan emosinya saat disebutkan } \\
\text { peristiwa yang membuat mereka marah. Sedangkan } \mathrm{W} \text { dan } \mathrm{R} \text { harus membuat balon } \\
\text { secara berulang-ulang karena mereka meniup dengan sangat kencang saat diminta } \\
\text { untuk mengeluarkan emosi yang dirasakan. }\end{array}$ \\
\hline Keenam & $\begin{array}{l}\text { F dan } \mathrm{R} \text { menunjukkan perilaku asertif yaitu mereka terlihat dapat membantu } \\
\text { temannya yang sedang mengalami kesulitan dan menawarkan bantuan tanpa diminta } \\
\text { oleh partispan lain. }\end{array}$ \\
\hline
\end{tabular}

Berdasarkan uraian di atas, dapat disimpulkan bahwa manfaat yang diperoleh dari kegiatan intervensi kelompok ini, antara lain subyek merasa lebih dapat melakukan kontrol diri, lebih mengusahakan kontak sosial secara positif dan mengurangi kecenderungan agresi verbal, dan saling menegur serta mengingatkan untuk melakukan perilaku yang baik. Misalnya pada saat $\mathrm{R}$ mengatakan kata-kata yang negatif, maka $\mathrm{F}$ dapat mengingatkan untuk tidak melakukan hal tersebut karena kata-kata negatif sudah dibuang ke laut pada saat sesi sebelumnya. Selain itu, ada pula feedback yang diperoleh dari group leader dan dari teman-temannya, masing-masing subyek dapat memperoleh penilaian positif tentang dirinya. Faktor dilakukannya intervensi kelompok pada umumnya dapat memberikan kesempatan pembelajaran pada orang lain, umpan balik positif masing-masing orang, dan kohesivitas yang semakin terbangun (Brabender, Fallon \& Smolar, 2004; Johnson, 2017).

Selain itu, faktor lain yang mempengaruhi jalannya program intervensi ini adalah kondisi setting atau lokasi dimana kegiatan dilaksanakan serta waktu pelaksanaan. Kehadiran murid lain dan lokasi di Lembaga Bimbingan Belajar X, merupakan satu sumber distraksi yang dapat mempengaruhi proses intervensi kelompok yang sedang berlangsung. (Magrabi, Li, Dunn \& Coerira, 2011; Sarafino, 2014). Waktu pelaksanaan sesi juga merupakan fakto yang mempengaruhi program ini karena waktu yang dilakukan pada saat anak baru pulang dari sekolah, hal ini berpotensi menganggu kualitas dari keikutsertaan anak yaitu atensi dan niat anak dalam program 
ini (Magrabi, Li, Dunn \& Coerira, 2011; Sarafino, 2014).

Hasil penelitian ini sejalan dengan penelitian sebelumnya bahwa penerapan Assertive Behavior Therapy dapat meningkatkan kontrol diri pada seseorang (Modahl, 2018). Hasil penelitian ini menambah jumlah literatur mengenai Assertive Behavior Therapy dalam menurunkan perilaku agresi khususnya bagi anak sekolah dasar. Meskipun demikian, penelitian ini masih jauh dari kata sempurna. Terdapat beberapa keterbatasan dari penelitian ini yaitu, jumlah sampel yang kecil, dana dan waktu yang terbatas.

\section{KESIMPULAN DAN SARAN}

Intervensi kelompok yang dilakukan dengan menggunakan metode assertive behavior therapy dapat menurunkan perilaku agresif pada kelima peserta yang mengikuti enam sesi group assertive behavior therapy yang diadakan. Penurunan perilaku agresi dapat dilihat dari hasil tes grafis Draw a Man, alat ukur Skala Perilaku Agresif, dan observasi yang dilakukan selama sesi intervensi berlangsung.

Perubahan dalam tes grafis yang terjadi dapat dilihat dari perubahan gambar orang yang dibuat oleh para peserta berdasarkan ukuran, letak, bentuk, arah, dan coretan garis yang dilakukan oleh para peserta. Hal-hal yang berubah pada gambar yang dibuat oleh peserta termasuk mengecilnya ukuran gambar orang secara keseluruhan, letaknya lebih ke arah tengah kertas, hilangnya bentuk bagian tubuh yang tajam, hilangnya arah kaki yang arahnya berlawanan, serta hilangnya garis yang bergerigi dan shading. Hal tersebut mengidikasikan adanya penurunan dalam perilaku agresif dan menunjukkan bahwa para peserta lebih mampu untuk mengendalikan dirinya. Pada Skala Perilaku Agresif, seluruh peserta intervensi juga menunjukkan penurunan skor agresi, meskipun tetap berada pada kategori perilaku agresi sedang, namun ada satu peserta yang skornya menurun hingga masuk ke dalam kategori perilaku agresi yang rendah. Pada sesi ke enam, para peserta sudah tidak lagi menunjukkan perilaku agresif secara verbal. Sebaliknya, hingga sesi ke enam, para peserta sudah bisa menegur atau mengungkap perasaannya ketika kesal dengan peserta lain, serta mampu meminta maaf ketika sudah melakukan sautu kesalahan. Para peserta juga menjadi lebih kooperatif dan lebih toleran terhadap satu sama lain. Para peserta mampu berdiskusi dan bekerja sama, serta membuat suatu keputusan bersama tanpa menunjukkan perilaku agresif.

\section{Saran}

Saran yang dapat diberikan oleh peneliti bagi penelitian selanjutnya, antara lain: (a) Pelaksanaan sesi dilakukan di dalam ruangan yang lebih tenang dan terkontrol, (b) Pelaksaan sesi dengan jadwal antar sesi yang berjarak konsisten, (c) Jumlah sesi dibuat dengan lebih variatif agar dapat membuat anak lebih merasa tertarik dalam mengikuti sesi yang diberikan.

\section{Ucapan Terima Kasih}

Penulis berterima kasih kepada partisipan yang terlibat dalam penelitian ini. Penulis juga mengucapkan terima kasih kepada pihak lembaga ' $\mathrm{X}$ ' yang sangat membantu dalam penyediaan ruangan dan membantu terlaksananya proses terapi.

\section{REFERENSI}

Alberti, R.E. (2015). Assertive behavior therapy. International Psychoterahpy Institute.

Brabender, V. A., Fallon, A. E., \& Smolar, A. I. (2004). Essentials of group therapy. Hoboken, NJ: John Wiley \& Sons. 
Dept. Of Education \& Science. (1997). On my own two feet: Assertive communication. Diunduh dari

https://www.google.co.id/url?sa=t\&rct=j\&q=\&esrc=s\&source=web\&cd=1\&cad=rja\&uac $\mathrm{t}=8 \&$ ved=0ahUKEwiT4ePN4_HXAhVEq48KHUXJB3gQFggoMAA\&url=http\%3A\%2F $\% 2 \mathrm{Fwww}$. sphe.ie\%2Fdownloads\%2Fmo2f\%2Fassertive_communication.pdf\&usg=AOv Vaw01_ngjAU-jWtsmtBAKnDB3

DeVito, J.A. (2013). The Interpersonal communication book, $13^{\text {th }}$ Edition. Boston: Pearson

Doverspike, W. F. (2013). How to be more assertive: a key to better communication. Diunduh dari https://www.google.co.id/url?sa=t\&rct=j\&q=\&esrc=s\&source=web\&cd=1\&cad=rja\&uac $\mathrm{t}=8 \& v e d=0$ ahUKEwix ofT6fHXAhUIpo8KHUB1DjkQFggoMAA\&url=http $\% 3 \mathrm{~A} \% 2 \mathrm{~F} \%$ 2Fdrwilliamdoverspike.com\%2Ffiles\%2Fhow_to_be_more_assertive.pdf\&usg=AOvVaw 2So_BTYKpqwbxlAB1TYg24

Geek Interview. (2011). Passive communication. Diunduh dari http://www.learn.geekinterview.com/career/communication-skills/passivecommunication.html

Gambrill, E. (2006). Critical thinking in clinical practice: Improving the quality of judgments and decisions. John Wiley \& Sons.

Gunarsa, S.D. (2007). Konseling dan psikoterapi. Jakarta: Gunung Mulia.

Johnson, B. (2017). Psychotherapy: Understanding group therapy. Retrieved from http://www.apa.org/helpcenter/group-therapy.aspx

Kazdin, A. E. (2013). Behavioral modification in applied setting. Long Grove: Waveland Press, Inc

Lioni, A., \& Pratiwi, T. I. (2013). Penerapan assertive training untuk mengurangi perilaku negatif berpacaran pada siswa kelas x-1 di sma negeri 1 porong. Jurnal mahasiswa teknologi pendidikan, 4(1).

Lorr, M., \& More, W. W. (1980). Four dimensions of assertiveness. Multivariate behavioral research, 15(2), 127-138.

Magrabi, F., Li, S. Y., Dunn, A. G., \& Coeira, E. (2011). Challenges in measuring the impact of interruption on patient safety and workflow outcomes. Methods of information in medicine, 50(5), 447-453.

Milovanovic, R., Miladinovic, I. C., \& Stojanovic, B. (2017). Assertiveness of prospective teachers and preschool teachers. Journal plus education, 16(2), 289-303.

Murray, H., \& Lang, M. (1997). Does classroom participation improve student learning. Teaching and learning in higher education, 20(1), 7-9.

Ollendick, T. H. (1983). Reliability and validity of the revised fear survey schedule for children (FSSC-R). Behaviour research and therapy, 21(6), 685-692.

Papalia, D.E. \& Feldman, R.D. (2011). A childs world: Infancy through adolescence. Boston : McGraw Hill.

Papalia D.E., Olds, S.W, \& Feldman, R.D. (2009). Human development (Perkembangan Manusia edisi 10 buku 2). Jakarta: Salemba Humanika.

Rotheram-Borus, M. J., Bickford, B., \& Milburn, N. G. (2001). Implementing a classroom-based social skills training program in middle childhood. Journal of educational and psychological consultation, 12(2), 91-111.

Santosa, J.S. (1999). Peran orang tua dalam mengajarkan perilaku asertif pada remaja. Anima: indonesia psychological journal

Sarafino, E. P. (2014). Health psychology: Biopsychosocial interactions (7th ed.). Retrieved from https://books.google.co.id/books?id=m9hwDFOU1E8C\&pg=PT249\&lpg=PT249\&dq=so urce+of++external+distraction+during++psychological+intervention\&source $=$ bl\&ots $=5 \mathrm{~S}$ xeTeJcVx\&sig=liAoofF8XKsqQzIoJjS02TopYX8\&hl=en\&sa=X\&ved=0ahUKEwi68d- 
Menurunkan Perilaku Agresi Verbal pada Anak di Lembaga X

1p-TUAhVJKY8KHXccDgsQ6AEIQjAF\#v=onepage \&q=source of external distraction during psychological intervention $\& \mathrm{f}=$ false 